\title{
The social construct of climate and climate change
}

\author{
Nico Stehr ${ }^{1}$, Hans von Storch ${ }^{2}$ \\ 'Department of Sociology, The University of Alberta, Edmonton, Alberta, Canada T6G 2H42 \\ ${ }^{2}$ Max-Planck-Institut für Meteorologie, Bundesstr. 55, D-20146 Hamburg, Germany
}

\begin{abstract}
Different time scales of climate change and their differential perception in society are discussed. A historical examination of natural climate changes during the past millennium suggests that short-term changes, especially crucial changes, trigger a significant response in and by society. Shortterm changes correspond to the 'time horizon of everyday life', that is, to a time scale from days and weeks to a few years. The currently anticipated anthropogenic climate changes, however, are expected. to occur on a longer time scale. They require a response by society not on the basis of primary experience but on the basis of scientifically constructed scenarios and the ways in which such information is represented in the modern media, for example. Socio-economic impact research relies on concepts that are based on the premise of perfectly informed actors for the development of optimal adaptation strategies. In contrast to such a conception, we develop the concept of a 'social construct of climate' as decisive for the public perception of scientific knowledge about climate and for public policy on climate change. The concept is illustrated using a number of examples.
\end{abstract}

KEY WORDS: Climate and society - Climate change - Perception of climate Society and climate . Social construct of climate $\cdot$ Climate policy

\section{INTRODUCTION}

In modern societies, the impact of climate and, in particular, possible future anthropogenic climate change abruptly entered public consciousness a few years ago and continues to draw considerable public attention. In the natural sciences the view prevails that the absence of an effective response to the threat of a changing global environment results from the failure to understand the physics of ongoing natural processes. We suggest that this approach represents a flawed understanding of the dynamics of public discourse, to which problems are granted entry only as social constructs that compete for public attention with other environmental as well as social, political and economic problems. The attentiveness of the public and of policy-makers to such issues depends on their perceived threat to society. The required evidence for such an 'immediate threat' of climate is primarily supplied by certain extreme natural events which are independent of real climate change (such as the intense drought in 1988 in the United States or the storm season in 1993 in northern Europe).
In this paper we discuss the concept of the 'social construct of climate and climate change', its relationship to the physical climate and its impact on the design of climate policy. We illustrate our idea by comparing the present situation with historical analogues from the Middle Ages and from the first half of the present century.

The essay is organized as follows. First, physical aspects of climate and its natural variability and the state of our knowledge about expected anthropogenic climate change are briefly discussed. In the next section we define the social construct of climate and (anthropogenic) climate change, and in the section following that we deal with the dynamics of the social construct of climate by considering the interrelation between the perception of climate change, modern cultural industries and the public sphere. We then discuss the technocratic approach of designing a climate policy and contrast these ideas with past and present actual developments. Finally, in the last section we present the options available for a more realistic and workable approach to climate policy. 


\section{THE CLIMATE SYSTEM AND ITS NATURAL VARIABILITY}

The physical state of the climate, and in particular the state of the lower troposphere which affects society most significantly, varies on a wide range of time scales due to various natural processes. This variability is significant for 2 reasons: first, it may mask any possible human-made signal (Hasselmann 1993); second, it has forced earlier societies to confront the threat of climate change, and as a result we are able to compare the response of the present-day society with the response of earlier ones.

The shortest time scales are days, with weather events such as storms or blocking events. The frequency and intensity of these events are mostly randomly distributed. There is always a chance for a ' 1000 year' storm to happen (cf. Hoyt 1981). The probability of such an event is small but not zero. Also, on somewhat longer time scales of weeks, droughts and floods may happen with a small but not zero probability. More precisely, the probability that at any a priori specified location a strong storm, a drought or a flood will happen is small. But the probability that at some location in the world there will be a strong storm, a drought or a flood is no longer small.

On time scales of years, decades and even longer periods the climate system also exhibits marked variations. The dynamics of these 'low-frequency' variations are so far not well understood, but a robust concept within which these variations appear sensible is the 'stochastic climate model' approach, which proposes the redness of the climate spectra to be a response of a slow system to short-term random forcing (Hasselmann 1976).

\section{ANTHROPOGENIC CLIMATE CHANGE}

Today, when climate change has become a household term, it is well worth reminding ourselves of the real material basis of the scenario of $\mathrm{CO}_{2}$-induced climate change. The state of the discussion was summarized in 1990 and 1992 by the highly valued Intergovernmental Panel of Climate Change (IPCC), a committee made up of reputable natural scientists (Houghton et al. 1992). This panel concluded that there has in fact been a dramatic increase in the atmospheric concentration of radiatively active gases since industrialization and that this increase is likely to continue unless political measures are instituted to reduce emissions. Theoretical reflection as well as extensive (and expensive) experiments with detailed climate models have led to the prognosis that the increased concentration of radiatively active gases will cause a change of the global climate. Most scientists expect an increase in the overall near-surface temperature (in the range of a few tenths of a degree per decade) and an overall rise in the sea level (in the range of a few decimeters per century).

This expectation has not (yet) been unambiguously supported by observational studies because of a lack of adequate as well as sufficiently long-term and homogenous observational data. Hegerl et al. (1994) have shown, by using a sophisticated statistical methodology involving the use of several facets of climate model results, that the latest temperature increases are outside the expected range of natural variability - and must therefore have been instigated by external factors, for instance by the greenhouse effect. This finding depends quite heavily on some estimates derived from climate models, so that the analysis by Hegerl et al. (1994) is rightly challenged. However, it is generaliy expected that the evidence to be gathered in the next years will be sufficient to attribute the observed changes to the human emission of gases and particles into the global environment.

In short, the 'signal' produced by greenhouse warming is on the verge of emerging from the ocean of 'natural climate variability' as described in the previous section. The general near-surface warming on Earth in the last 100 years or so, with particularly high warming rates in the past few decades, is likely due to the anthropogenic greenhouse effect, both in terms of pattern and intensity. But it is possible that this 'signal' is entirely created by natural processes - and the strength of the recent signal is indeed comparable to that in the 1920s-30s, when nobody claimed any anthropogenic climate change had occurred (see Hegerl et al. 1994). Because of these uncertainties, the IPCC offered the following cautionary note in its 1990 report:

[T/his warming is broadly consistent with predictions of climate models, but it is also of the same magnitude as natural climate variability. Thus the observed increase could be largely due to this internal variability... [T] he unequivocal detection of the enhanced greenhouse effect from observations is not likely for a decade or more.

It should be stressed that all global warming scenarios with some spatial detail are based on 'climate models' that are the best available research tools for the study of climate variability and the design of scenarios of human-made climate change. Such climate models approximate the real climate system and are based on detailed 'general circulation models' of the ocean, the atmosphere and other components of the climate system. The oceanic and atmospheric components are relatively reliable elements in these complex climate models. Other components, such as the earth's surface 
or sea ice, are much less reliably represented. (For more details refer to e.g. Washington \& Parkinson 1991.)

All climate models are somehow conceptually related, not only through their basic first principles but also in their choices of how to parameterize various processes which cannot be represented directly (such as the turbulent exchange in boundary layers). Therefore similar scenarios derived from 2 different climate models, say from the Geophysical Fluid Dynamics Laboratory, Princeton, NJ, USA, and the Max-PlanckInstitut für Meteorologie, Hamburg, Germany, do not supply the scientific community with 2 independent sources of evidence that these scenarios might be correct.

Because of limited observational data it is not possible to rigorously test the climate models in order to demonstrate that they are capable of simulating (natural and human-made) climate variability realistically. Certainly, these models have been examined with respect to weather forecasting, El Niño forecasting, the simulation of present-day climatology and other applications. Their success in doing so, together with the fact that a significant portion of the models are based on first principles, provides us with some confidence. We believe that the models describe significant sensitivities in the climate system - but we do not really know it.

\section{THE SOCIAL CONSTRUCT OF CLIMATE AND CLIMATE CHANGE}

Society obviously depends on climate. But what is the effect of climate anomalies on society? We claim that this dependency is largely conditional to the time scale. 'Slow' time scales of something between 1 and $30 \mathrm{yr}$, which are beyond the time horizon of everyday life, are relevant for climate change, be it human-made or due to naturai processes. 'Fast' time scales, which are within the time horizon of everyday life, feature 'normal extremes' such as a '100 year storm surges' and multi-year anomalies like the cold spell in Europe during the last third of the 17 th century (Lindgren \& Neumann 1981).

The slow variations appear to have had little social and economic impact in the past. Fast variations have produced irreversible social, economic and cultural changes either by virtue of their impact on the natural environment of a society (e.g. land lost to the sea, desertification) or by demographic (rural exodus, mortality), cultural (emerging values) and economic changes (standard of living, trade patterns, the organization and location of production, agricultural yields).
Within the context of human-made climate change the slow time scales matter. As a result, we encounter 2 competing images in the arena of public discourse: the (slow) climate and its changes, and the (fast) weather and climate variability (including naturally occurring rare extremes and multi-year anomalies). These 2 cognitive entities are (physically) not at all, or at most weakly, related to each other. (Climatology is just now beginning to investigate the character of the nature of interrelation of the slow and fast time scale variabilities.) Our assertion is that society is biased in its attention towards the extremes and therefore mistakes extremes as climate change.

The at times almost uncontested interpretation of climate variations by societal authorities also is an important factor in the social response to an observed real or imaginary climate change. Such authorities may be scientists or charlatans but also the modern media, superstition, or religious institutions. Another important factor is, at any given time, the competition for public attention and solutions among contemporaneous social problems. There are many more or less urgent social problems which compete with the threat of climate change for scarce public attention and resources (e.g. Ungar 1992). Because of these processes, the public never obtains a perspective of climate as elaborated by the physical experts in an unmediated fashion but only a filtered image of it, namely the social construct of climate. We suggest that the climate and its social construct can be independent entities or events.

\section{CULTURAL INDUSTRIES, THE PUBLIC SPHERE AND THE PERCEPTION OF CLIMATE CHANGE}

Climatologists concerned with their scientific capacity to reliably derive scenarios of climate change have devoted a significant part of their literature to the overall problem of the uncertainties that surround such scenarios now and in general. In spite of this generally cautious stand there are climatologists who stress the risks for society of responding to such contestable conjectures with incredulity (e.g. Schneider \& Mesirow 1976, Kellogg 1978).

However, neither the manufacture nor the communication of research on climate and climate change occurs in a social vacuum. These activities both within and external to science are linked to various social practices ordered across time and space. In the following we will only touch on 2 major aspects of these social practices, which affect the ways in which scientific conjectures can be communicated to the public without encountering disinterest or disbelief. Particularly the communication of research findings to indi- 
viduals and groups outside of the scientific community is affected significantly by social processes that influence the organization of images and ways in which people make sense of the dynamics of society and natural processes. Research results, however carefully constructed, are filtered and transformed in various patterned ways. These processes, e.g those within cultural industries as one of the major sources of information and meaning in modern society, mediate and reconstruct scientific findings generated by climate researchers. And the output of these processes will determine how these findings ultimately are interpreted by the public at large as well as by groups such as social movements (cf. Lowe \& Morrison 1984, Lacey \& Longman 1993, Singer \& Endreny 1993).

Cultural industries do not merely provide access to the broadest range of information, reasoned advice and interpretative analysis on various topics in order to facilitate rational discussion and public decision (as might be the case in some ideal sense). At best, such a conception of the communication sector of modern society provides for a desirable yardstick against which its actual performance may be assessed. Since cultural industries are subject to various other significant constraints, not least among them economic and ideological pressures, their actual performance, the range and depth of coverage, most often does not sustain and support a public sphere in which research findings are represented and reinterpreted in a manner that prevent them from being radically transformed and in which cautionary notes and qualifications are completely ignored (see Gamson 1993).

In short, the desire of climatologists to communicate their findings in an unequivocal fashion for public discourse encounters, first, the obstacle of modern cultural industries and their peculiar contingencies. Second, the public or, better, various segments of the public interpret the research findings in ways which may or may not correspond to the intentions of the researchers.

When researchers have examined the public response to social and environmental problems (such as drug use or public encounters with diseases or disasters), 2 perspectives have dominated the study of the collective or individual response to social issues, namely the objectivist and the constructivist approaches (cf. Merton \& Nisbet 1966, Douglas \& Wildavsky 1982, Douglas 1992).

The objectivist approach is based on the premise that the 'threat' in question, for example climate change, is quite real, can be demonstrated scientifically and likely will cause serious harm to human life and society. The constructivist approach, in contrast, concentrates on the public perception of the risks and emphasizes the ways in which perception and assess- ment of risks is influenced by social and cultural factors. The first view tends to focus on the manufacture (by experts) of conjectures, stressing their objective, undeniable consequences, while the second approach chooses to emphasize the reception (by laymen) of such hypotheses in different social, cultural and political contexts. The disparities and discrepancies between the 2 forms of inference often are highlighted and lead to the conclusion that a generally 'true' definition of risks and threats is at best a dubious undertaking (e.g. Rayner \& Cantor 1987).

In general, however, research into risk communication, the public perception of social problems and threats posed by various natural or social events takes place at a pragmatic middle ground between the 2 extremes, denying neither that threats are objective nor that the public response may at times vary considerably and/or chose to ignore such warnings altogether (e.g. Goode 1989). Lacey \& Longman (1993, p. 239), for example, conclude in their analysis of recent press coverage in England of environmental and development issues, 'The coverage of global warming which was at a height in 1989 and 1990 had dwindled to almost pre-autumn 1988 levels by spring 1991. This was a general phenomenon across the range of newspapers considered. This is a disturbing feature of press coverage. It means that despite the worsening of the actual condition (greenhouse gas emissions and global warming) and no indication that public concerns had diminished the press "gatekeepers" have decided that the issue is no longer newsworthy.' The literature on risk communication often aims to find ways of more effectively communicating 'objective' expert information to a public whose perception is 'mediated' by various cultural processes (cf. Wiedemann 1991).

However, such an approach to the communication and public perception of risks simplifies - as we already have tried to demonstrate in a general sense complicated matters to a considerable extent. To begin with, the communication of information, especially the extent to which conjectures are 'believed', is rarely a matter of the 'quality' (for instance in the sense of the objectivity or scientificity) of its contents. On the contrary, the quality of rapidly changing or enduring social relations and of salient cultural resources (e.g world views) among active agents in science, cultural industries and the public sphere matter more. The formulation of risks or the assessment of hazards, the reporting and interpretation of these issues and, last but not least, the public response to these accounts involves at each juncture active agents with distinct purposes engaged in arriving at their interpretations of what then become socially constructed meanings. The outcome is a complicated form of discourse and inter- 
section of social contexts that cannot easily be influenced to assure that a specific framing of the issues and of the conclusions prevails. The manufacture of and subsequent response to objective claims formulated in statistical terms, for example, and generated by climate research is no exception. Climatologists construct objective conjectures about climate according to certain social practices and standards prevailing and accepted in the scientific community generally. Objective and constructivist features of scientific scenarios and expected risks engendered by climate change tend to mix and blend into each other (cf. Krohn \& Krücken 1993), and this is especially the case as the scenarios enter the arena of public discussion in the form of 'predictions'.

\section{CLIMATE POLICY}

The significant implication of distinguishing between climate and its social construction is that it is only the social construct which ultimately shapes climate policy, whereas the climate itself plays no or only an insignificant role in the process of designing a climate policy.

In the scientific community, economic concepts and perspectives have dominated in the discussions on how to respond to the possibility of human-made climate change. And in the intellectual tradition of neoclassical economics, a perfectly informed society is expected to design an 'optimal' response strategy (e.g. Nordhaus 1991, Tahvonen et al. 1994). A prototype would be a schematic depiction of the relationship between the global environment and society in which two entities, 'climate' and the 'socio-economy', are assumed to interact with each other via environmental parameters, such as temperature or precipitation (which, in turn, affect the biosphere and thus man), and the emission of radiatively active gases. The 'costs' of a climate change ('damage' or 'adaptation' costs) as well as the costs of changing the economy required to avoid or diminish climate change ('abatement' costs) are, at least in principle, known and can be quantified (in money or moral units). This quantification is done according to social norms and political decisions that represent societal preference and utility scales. An 'optimal' climate policy is then designed to minimize the total costs taking into account the damage costs and the abatement costs (Hasselmann 1990).

We would like to contrast such a viewpoint - that best is called the 'technocratic' approach - with a perspective according to which it is not climate itself but the social construct of climate that is the dominant factor. We suggest that society has failed to pay sufficient attention to the real and thus slow climate-change sig- nal. Instead, society responds to the social construct of climate change, thereby mistaking natural extremes as indicators of climate change. We illustrate our conception by way of 3 examples.

Between 1315 and 1317 the harvest failed in England, mainly because of persistent summer precipitation. As a consequence, there was a famine and diseases spread (killing up to $10 \%$ of the population). The authorities, essentially the Church, had warned its subjects prior to the failed harvests that God would punish them if they did not adopt higher moral standards in their life. The climatic extreme that occurred was interpreted as a climate change. The (only) believable factor controlling climate was said to be God, and the change in the climate thus reflected God's anger and revenge. Because of the life-threatening character of the implications of climate change (famine, death), 'adaptation' was not an acceptable climate policy. The only available option was 'abatement', which meant to put an end to God's wrath. And exactly that was the social response at the time. As one social historian (Kershaw 1973) reports

[T]he Archbishop of Canterbury ordered the clergy to perform solemn, barefooted processions bearing the Sacrament and relics, accompanied by the ringing of the bells, chanting of the litany, and the celebration of the mass. This was in the hope of encouraging the people to atone for their sins and appease the wrath of God by prayer, fasting, almsgiving, and other charitable work.

This climate policy was perceived as successful: the climate anomaly disappeared, the harvests recovered. The social construct of climate and climate were clearly unrelated in this case. Another example of a social construction of climate change during the Middle Ages might make reference to witches who were widely perceived to modify climate either directly through witchcraft or indirectly by causing God's anger about failure to take action against the evil practice of the witches (Behringer 1988).

The idea that emissions of greenhouse gases might artificially change the global climate, with an increase in the near-surface temperature, was already proposed in the late 19 th century by the Swedish scientist Arrhenius (1896). For many years this notion was considered an intellectually appealing but practically unimportant thought. Only in the 1970s were the possible impacts of the anthropogenic greenhouse effect discussed more seriously. In the 1980s the 'greenhouse effect' became the most important topic in climate research, with increasing funding ever since. The public suddenly appeared to accept the greenhouse problem as a significant issue in the aftermath of several extreme events.

The North American drought in 1988 was crucial in North America. During a hearing of the United States 
Senate, the well-known climate researcher James Hansen declared the drought with ' 99 per cent certainty' to be related to the anthropogenic climate change (Schneider 1989). This statement had a poor substantive basis and appears dubious in view of the absence of further droughts in subsequent years the headlines in the summer of 1993 were dominated by reports of dramatic flooding in the same regions). An alternative explanation for the drought, that it resulted from a response to a peculiar configuration of sea-surface temperature anomalies in the North Pacific, was put forward by other climatologists (Trenberth et al. 1988)

In the spring of both 1991 and 1993, northern Europe experienced a series of severe storms which caused significant damage. The storms were interpreted by the media as an indicator of the predicted climate change, and even reputable scientists declared more or less openly that the frequency of intense storms had increased and would further increase as a response to human emissions of greenhouse gases. A statistical analysis of the frequencies of storms in the North Sea area and other parts of the North Atlantic area (von Storch et al. 1993) in the past 100 yr revealed no such systematic changes. The result was Iargely disregarded by the media even though a short version was published in Nature (Schmidt \& von Storch 1993).

A further example refers to the decades of the 1920 s and $1930 \mathrm{~s}$ in the Northern Hemisphere. Within 2 decades, from 1911-20 to 1931-40, the annual mean temperature in the Northern Hemisphere increased by $0.3^{\circ} \mathrm{C}$. Local changes were as high as $1^{\circ} \mathrm{C}$ and more. The public did not take notice of this change, although its magnitude was comparable to the present change (the Northern Hemisphere mean temperature change from the 1971-80 decade to the 1981-90 decade was only $0.25^{\circ} \mathrm{C}$ according to the most reliable estimates). We suggest that climate change in those years simply failed to become a major public concern because of the competition posed by traumatic social problems such as the societal reorganization after the First World War, the economic depression and the formation of totalitarian regimes.

\section{OPTIONS FOR CLIMATE POLICY}

We therefore argue that any climate policy is subject to the following dilemmas:

- If slow climate change takes place and the public is has been warned of such a change by the political and/or scientific authorities, then the real slowly evolving signal will hardly be noticed. Instead the public will accept extremes, which are consistent with (but in fact mostly unrelated to) the warnings, as 'proofs' of the reality of climate change. An active abatement or adaptation policy can be designed, but whether this policy will be adequate remains an open question.

- If the climate changes gradually and the public is not concerned about such a change, passive adaptation will take place. The naturally occurring extremes are then accepted by the public as unavoidable natural interruptions

- If climate does not change, but the public nevertheless expects a climate change, then any extreme (or multi-year anomaly) will be interpreted as evidence of the climate change and a climate policy will be instituted according to the norms accepted in a given society and historical period.

- If the climate is stationary and the society does not expect changes, extremes will create no demand for a climate policy.

The last configuration is the most frequent in history In most historical writings, the weather and weatherrelated catastrophes are discussed mostly for reasons of completeness (e.g. Weikinn 1958-61). The case 'England 1314-1317' belongs to the third category, the case 'Northern Hemisphere 1920-1930' must be assigned to the second category and the present situation may belong to the first or the third groups.

We conclude that:

- The physics of climate change are largely incomprehensible to the public. The anticipated climate change occurs on time scales much longer than the 'time horizon of everyday life' so that people must respond to threats they actually do not experience personally. Even social groups closely dependent on environmental factors sensitive to climate change, such as the agricultural sector or people living in coastal areas, find it difficult to deal with a slow but steady climate change.

- The notions of climate and social construct of climate and climate change, while not contradictory, are often independent of each other.

- A 'reasonable' societal reaction to the climate change induced by humans, which, at least in principle, can be controlled by political measures, cannot realistically be expected. Such a reaction perhaps could be produced by a skillful manipulation of the 'misunderstanding' of extremes (it appears that such an option does exist in the minds of some natural scientists) or by way of a vigorous public campaign.

Research on global environmental change in general and on climate change in particular is still widely considered essentially a subject area of the natural sciences. Despite the recent well-publicized critique of the notion of global warming by a minority of climate researchers and others (e.g. Salmon 1993), the establishment and representation of consensus on climate change by the natural sciences (IPCC 1990, Houghton 
et al. 1992) continues to exert the most influence in the international political arena. But it also is necessary to critically examine the notion that the scientific authority of knowledge on climate change is somehow natural rather than constructed within the scientific community.

In any case, there is a substantial need for interaction between the strictly separated and persistently sovereign domains of natural science climate research and social research in order to understand the interdependencies between climate and the social construction of climate. We need, for example, more historical comparisons with present situations. In addition, empirical analyses of the societal perception of climate and weather are required to begin to answer key questions, such as 'What is so special about the climate problem that it at times appears to be more serious than most other social problems?'

\section{LITERATURE CITED}

Arrhenius SA (1896) On the influence of carbonic acid in the air upon the temperature of the ground. Phil Mag J Sci 41:237-276

Behringer W (1988) Hexenverfolgung in Bayern. R Oldenbourg Verlag, München

Douglas M (1992) Risk and blame. Essays in cultural theory. Routledge, London

Douglas M. Wildavsky A (1982) Risk and culture an essay on the selection of technological and environmental dangers. University of California Press, Berkeley

Gamson WA (1993) Talking politics. Cambridge University Press, Cambridge

Goode E (1989) The American drug panic of the 1980s: social construction or objective threat? Violence Aggression Terrorism 3:327-348

Hasselmann K (1976) Stochastic climate models. Part I. Theory. Tellus 28:473-484

Hasselmann K (1990) How well can we predict the climate crisis? In: Siebert $H$ (ed) Environmental scarcitythe international dimension. JCB Mohr, Tübingen, $p$ $165-183$

Hasselmann K (1993) Optimal fingerprints for the detection of time-dependent climate change. J Clim 6:1957-1971

Hegerl GC, von Storck H, Hasselmann K, Santer BD, Cubasch $\mathrm{U}$, Jones PD (1994) Detecting anthropogenic climate change with an optimal fingerprint method. Max-PlanckInstitut für Meteorologie Rep 142, Hamburg

Houghton JT, Callander BA, Varney SK (1992) Climate Change 1992. The supplementary report to the IPCC Scientific Assessment. Cambridge University Press, Cambridge

Hoyt DV (1981) Weather 'records' and climate change. Clim Change 3:243-249

Editor: G. Esser, Gießen, Germany
IPCC (1990) Scientific assessment of climate change. The policymakers' summary of the Report of Working Group I to the Intergovernmental Panel on Climate Change. World Meteorological Organization/United Nations Environment Programme, Geneva

Kellogg WW (1978) Global influences of mankind on the climate. Gribbin J (ed) Climatic change. Cambridge University Press, Cambridge, p 205-227

Kershaw I (1973) The great famine and agranan crisis in England, 1315-1322. Past Present 59:3-50

Krohn W, Krücken G (1993) Risiko als Konstruktion und Wirklichkeit. In: Krohn W, Krücken G (eds) Riskante Technologien: Reflexion und Regulation. Einführung in die sozialwissenschaftliche Risikoforschung. Suhrkamp. Frankfurt am Main, p. 9-44

Lacey C, Longman D (1993) The press and public access to the environment and development debate. Sociol Rev 41:207-243

Lindgren S, Neumann J (1981) The cold and wet year 1695 - a contemporary German account. Clim Change 3:173-187

Lowe P, Morrison D (1984) Bad news or good news: environmental politics and the mass media. Sociol Rev 32:75-90

Merton RK, Nisbet R (eds) (1966) Contemporary social problems. Harcourt Brace \& World, New York

Nordhaus WD (1991) To slow or not to slow: the economics of the greenhouse effect. Econ J 101:920-937

Rayner S, Cantor R (1987) How fair is safe enough? The cultural approach to societal technology. Risk Anal 7:3-9

Salmon J (1993) Greenhouse anxiety. Commentary 45:25-28

Schmidt $H$, von Storch $H$ (1993) German Bight storms analysed. Nature 365:791

Schneider S (1989) Global warming: are we entering the greenhouse century? Sierra Club Books, San Francisco

Schneider SH, Mesirow LE (1976) The Genesis Strategy: climate and survival. Plenum Press, New York

Singer E, Endreny PM (1993) Reporting on risk. How the mass media portray accidents, diseases, disasters, and other hazards. Russell Sage Foundation, New York

Tahvonen O, von Storch $H$, von Storch J (1994) Economic efficiency of $\mathrm{CO}_{2}$ reduction programs. Clim Res 4:127-141

Trenberth K, Branstator GW, Arkin PA (1988) Origins of the 1988 North American drought. Science 242:1540-1645

Ungar $S$ (1992) The rise and relative fall of global warming as a social problem. Sociol Quart 33:483-501

von Storch H, Guddal J, Iden K, Jonsson T, Perlwitz J, Reistad $M$, de Ronde J, Schmidt $H$, Zorita $E$ (1993) Changing statistics of storms in the North Atlantic? Max-Planck-Institut für Meteorologie Rep 116. Hamburg

Washington WM, Parkinson CL (1986) An introduction to three-dimensional climate modelling. University Science Books, Mill Valley, CA

Weikinn C (1958-61) Quellentexte zur Witterungsgeschichte Europas von der Zeitwende bis zum Jahre 1850, 4 Volumes. Akademie Verlag, Berlin

Wiedemann PM (1991) Strategien der Risiko-Kommunikation und ihre Probleme. In: Jungermann $H$, Rohrmann B, Wiedemann PM (eds) Risikokontroversen. Konzepte, Konflikte, Kommunikation. Springer-Verlag, Berlin

Manuscript first received: June 29, 1994

Revised version accepted: November 21, 1994 